\title{
Aprendizaje y retos de la acción social: sistematización de la experiencia de la Escuela de Psicología, Universidad de Costa Rica
}

\author{
Learning and Challenges of Social Action: Systematization \\ of the Experience of the School of Psychology, University \\ of Costa Rica
}

\author{
Adriana Maroto-Vargas \\ Universidad de Costa Rica \\ San José, Costa Rica \\ adriana.maroto_v@ucr.ac.cr \\ https://orcid.org/0000-0002-9899-9566 \\ Daniela Carrillo-Valverde \\ Universidad de Costa Rica \\ San José, Costa Rica \\ daniela.carrillo@ucr.ac.cr
}

Recibido: 25/06/2020 • Aceptado: 21/09/2020

\begin{abstract}
Resumen. La acción social, pilar de la universidad pública latinoamericana, se ha desarrollado desde diferentes modelos. Tomando ese marco teórico e histórico como referencia, el artículo presenta una sistematización crítica de la experiencia de acción social de la Escuela de Psicología de la Universidad de Costa Rica, durante el período 2000-2015. La investigación utilizó la sistematización de experiencias como enfoque metodológico desde el cual se hizo una interpretación crítica del proceso analizado. Se consultaron fuentes documentales y se realizaron catorce entrevistas, técnicas que permitieron la construcción de una línea del tiempo. Posteriormente, se realizó un taller que identificó los catorce ejes de discusión que se analizan en este artículo, entre los cuales se incluyen aspectos políticos, académicos y éticos de la acción social. Se concluye que la acción social tuvo un fortalecimiento a partir de que fue definida como una prioridad y se construyó un posicionamiento político que orienta el trabajo. Como retos principales se identificaron la divulgación, la definición de criterios de
\end{abstract}


cierre de proyectos, la sistematización y la evaluación, así como la construcción de una estrategia de articulación de proyectos entre sí y con las otras actividades sustantivas de la universidad (docencia e investigación).

Palabras clave: acción social, aprendizaje, Costa Rica, psicología, universidad.

\begin{abstract}
Social Action, a Latin America Public University pillar, has been developed from different models. As this theoretical and historical framework is taken as a reference, the article presents a critical systematization of the Social Action experience of the School of Psychology at the University of Costa Rica during the period 2000-2015. The research considered the systematization of experiences as a methodological approach from which a critical interpretation of the analyzed process was made. Documentary sources were consulted, and 14 interviews were conducted; these techniques allowed the construction of a timeline. Subsequently, a workshop was held, and it identified the 14 discussion axes analyzed in this article; they include political, academic, and ethical aspects of Social Action. It is concluded that Social Action had an improvement since it was defined as a priority, and a political position guiding the work was established. The main identified challenges were the dissemination, the definition of project closure criteria, the systematization and evaluation, as well as the construction of a project articulation strategy with each other and with other substantive activities of the university (teaching and research).
\end{abstract}

Keywords: Costa Rica, learning, psychology, social action, university.

\title{
Introducción
}

Este artículo surge del proyecto de investigación "Sistematización crítica de la experiencia de acción social de la Escuela de Psicología en el período 20002015", adscrito a la Escuela de Psicología de la Universidad de Costa Rica. En este se analizan los principales resultados, incluyendo las buenas prácticas o los factores clave para el fortalecimiento, así como las limitaciones identificadas, las cuales quedan planteadas como retos, teniendo como referente una revisión teórica sobre la extensión universitaria ${ }^{1}$ en América Latina.

\section{El surgimiento del modelo de la universidad pública latinoamericana}

El movimiento estudiantil en la ciudad de Córdoba (Argentina), en 1918, marcó un momento fundante en el modelo de universidad pública en América Latina,

\footnotetext{
En el artículo se utilizan extensión universitaria y acción social como sinónimos, ya que este último término es el que utiliza la Universidad de Costa Rica, pero el primero es el más usual entre las universidades latinoamericanas.
} 
el cual se ha conocido históricamente como la Reforma de Córdoba. Este fue el primer cuestionamiento serio de la universidad latinoamericana tradicional (Tünnermann, 2008; Acevedo, 2010), que respondía a los intereses de las clases dominantes, dueñas tanto de la universidad como del poder político y económico. La clase media emergente, representada en el movimiento estudiantil, defendió el acceso a la educación superior en una coyuntura caracterizada por la permanencia de un sistema autoritario, confesional y elitista que excluía a las personas de las clases sociales más bajas del acceso a la educación superior. "En la mayoría de países latinoamericanos, para el año 1950 apenas uno de cada cien jóvenes entre los 18 y 23 años llegaba a la universidad, ya que la exclusión operaba desde el nivel de la escuela primaria" (Rincón, 2007, p. 129).

Ese hito propagó el espíritu reformador por todo el continente americano, y si bien la implementación de los principios permanece en disputa hasta el día de hoy, marcó un rumbo a seguir. Los mayores logros de la Reforma de Córdoba se pueden ubicar en tres grandes ejes. El primero es la autonomía universitaria y su forma de gobierno, incluyendo la participación estudiantil. Rubens (2007) argumenta que la autonomía universitaria permite que el proceso educativo se aleje del poder eclesiástico y de los intereses del Gobierno. El segundo, los cuestionamientos y cambios en los métodos docentes que se habían centrado en la transferencia de conocimientos. Y, por último, la proyección política y social de la universidad, con lo cual se le ubica como un actor social en los procesos de transformación social, es decir, la universidad como una institución que no solo es responsable de la formación de profesionales, sino que debe comprometerse con los problemas sociales, políticos y económicos de los países (Acevedo, 2010; Pérez, Lakonich, Cecchi y Rotstein, 2009; Tünnermann, 2008).

Este modelo de universidad pública, que se construye en América Latina e incorpora la extensión universitaria como una actividad académica avocada a la transformación social, marca una diferencia con las universidades europeas y anglosajonas (Ortiz-Riaga y Morales-Rubiano, 2011). Este breve recorrido lo ubica como un modelo a defender, y no se trata de una visión simplista y homogeneizadora de la universidad en nuestra región, ya que existe una gran diversidad incluso a lo interno de cada institución.

En la Universidad de Costa Rica, el inicio de la década de los setenta se caracterizó por las discusiones sobre los fines de la universidad pública (Pérez y Meoño, 2005). Los acuerdos originados en el III Congreso Universitario (1973) modificaron los ejes universitarios, entre los cuales destacan la apertura 
Revista Universidad en Diálogo • Vol. 11, N. ${ }^{\circ}$ 1, Enero-Junio, 2021 • 103-133

ISSN 2215-2849 • EISSN: 2215-4752

URL: http://www.revistas.una.ac.cr/index.php/dialogo/index CORREO ELECTRÓNICO: universidadendialogo@una.cr DOI: http://doi.org/10.15359/udre.11-1.4

de más centros de investigación, el inicio de los programas de posgrado y la generación del vínculo sociedad-universidad. Se estableció así la docencia, la investigación y la acción social como la tríada orientada al logro del bien común (Universidad de Costa Rica, 1985).

No obstante, estos tres pilares académicos enfrentan realidades diferentes, y la acción social enfrenta grandes retos en cuanto a su reconocimiento académico y al presupuesto asignado. En el 2019, el presupuesto ordinario de la Universidad

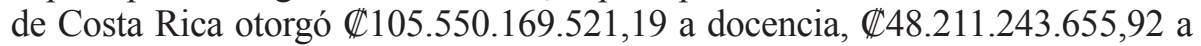
investigación y solo \9.827.463.274,90 a la acción social ${ }^{2}$ (Consejo Universitario, 2019). Es decir, del presupuesto directamente asignado a las tres actividades sustantivas, acción social solo recibió un $6 \%$. Adicionalmente, frente a las dificultades presupuestarias que enfrenta la institución en la actualidad, es una de las áreas en la que los recortes han sido más significativos (Muñoz, 2020). En su conjunto, estos datos muestran el lugar que se le brinda a la acción social, a pesar de que sus resultados son los que más se utilizan cuando la universidad debe defender su presupuesto frente al Gobierno y a la opinión pública.

\section{La conceptualización de la extensión universitaria en la universidad pública latinoamericana}

Como resultado de la Reforma de Córdoba, surgió la preocupación en las universidades latinoamericanas por trascender las fronteras institucionales y acercarse a la sociedad mediante la extensión. Sin embargo, la consolidación y el fortalecimiento de esta actividad académica requirió de varias décadas, y aún hoy es una práctica muy heterogénea desde su conceptualización y orientación estratégica (Fresán, 2004; Serna, 2007; Ortiz-Riaga y MoralesRubiano, 2011).

En la revisión bibliográfica se identifican diferentes modelos de extensión universitaria en las universidades públicas latinoamericanas. Estos se entienden como "la manera característica y distintiva en que una institución de enseñanza superior, asumiendo su función social, comparte su cultura y conocimientos con personas, grupos o comunidades marginados o vulnerables" (Serna, 2007, p. 2). Por tanto, involucran posicionamientos teóricos, pedagógicos, políticos y metodológicos respecto a los procesos de enseñanza, la generación de conocimiento y la relación entre la universidad y la sociedad (Tommasino y Cano, 2016).

\footnotetext{
Los montos se refieren a los Programas 01 Docencia, 02 Investigación y 03 Acción Social. Adicionalmente, en las Sedes Regionales se destinan otros fondos a estas actividades sustantivas, pero que en el presupuesto universitario no se desglosan como tal.
} 
En las instituciones universitarias se utilizan diferentes términos para referirse a la extensión, entre los que se incluyen los siguientes: articulación, vinculación, responsabilidad social universitaria, compromiso social, intensión universitaria, extensión crítica y ecología de saberes. A estos se debe añadir el de acción social en la Universidad de Costa Rica. Otro elemento de análisis es la gran diversidad de actividades que se realizan bajo el nombre de extensión: procesos de organización comunitaria, asesoramiento, educación continua, voluntariado, entre otras. Se trata, por tanto, de un concepto en disputa que refiere a "articulaciones discursivas que pugnan por dotar de sentido el vínculo universidad-sociedad en función de determinados intereses, concepciones, finalidades, implicaciones" (Tommasino y Cano, 2016, p. 10).

Existen cuatro modelos de extensión universitaria que, aunque tienen diferentes denominaciones, comparten características, tal como se muestra a continuación.

\section{El modelo altruista}

Se posiciona en las primeras décadas del siglo XX como resultado directo de la Reforma de Córdoba. Se concebía la extensión desde una postura caritativa en la que la población universitaria realizaba acciones desinteresadas en favor de los sectores marginados (Ortiz-Riaga y Morales-Rubiano, 2011). Se asumió como una responsabilidad del estudiantado y se reprodujeron las formas tradicionales de la enseñanza, basadas en un abordaje magistral en el que el conocimiento universitario era una voz respetada y escuchada desde las comunidades, sin propiciar ningún intercambio (Carlevaro, 2008).

\section{El modelo divulgativo o difusionista-transferencista}

La finalidad es la difusión del conocimiento y no existe interés por el tipo de vínculo que se genera. Busca acercar a la población a los adelantos técnicos y científicos y a las expresiones culturales que se producen desde la universidad, institución que se erige como un centro de poder que no consulta las auténticas necesidades de los sectores más vulnerables. Por ende, la extensión se convierte en una invasión cultural: la institución impone juicios, concepciones y valores, se espera una actitud pasiva de las personas con las que se relaciona y establece un vínculo caracterizado por el asistencialismo. En consonancia, no se priorizan los sectores con que se trabaja y suele ser común la atención de los intereses de los agentes productivos y los dueños de capital, especialmente en el circuito ciencia-innovación-aplicación (Fresán, 2004; Ortiz-Riaga y Morales-Rubiano, 2011; Tommasino y Cano, 2016). 
Revista Universidad en Diálogo • Vol. 11, N. ${ }^{\circ}$ 1, Enero-Junio, 2021 • 103-133

ISSN 2215-2849 • EISSN: 2215-4752

URL: http://www.revistas.una.ac.cr/index.php/dialogo/index CorReo ElECTRÓNICO: universidadendialogo@una.cr DOI: http://doi.org/10.15359/udre.11-1.4

\section{El modelo concientizador, la extensión crítica o el enfoque social}

Es influenciado por los procesos emancipatorios de los movimientos obreros, campesinos y estudiantiles de América Latina, particularmente por los aportes de PauloFreirey Orlando Fals Borda. Se parte de un posicionamiento epistemológico en el que tanto las instituciones como las comunidades son actores activos en la producción de conocimiento, ya que se construye en el encuentro entre el saber académico y el saber popular, lo que genera conocimientos contextualizados (Pérez, Lakonich, Cecchi y Rotstein, 2009; Tommasino y Cano, 2016). Esto no solo beneficia a las comunidades, sino también a las universidades, porque les permite identificar con precisión necesidades e inquietudes, así como su incorporación en el quehacer cotidiano para trabajar en la solución de los problemas, articulando de manera estrecha con la docencia y la investigación (Fresán, 2004; Ortiz-Riaga y Morales-Rubiano, 2011).

La vinculación con el entorno social es parte de una formación académica que trasciende el enfoque meramente técnico-profesional (Tommasino y Cano, 2016; Malagón, 2006). Es un proceso crítico y dialógico que incide en la transformación social, pone en juego las habilidades, los conocimientos, las actitudes y los valores, es decir, no solo tiene implicaciones en lo intelectual, sino también en lo emotivo. Dicho en otras palabras, se trata de una formación humanista que genera una participación consciente que transforma el proceso de aprendizaje (Serna, 2007; Ortiz-Riaga y Morales-Rubiano, 2011; Tommasino y Cano, 2016).

El fin es contribuir a los procesos de organización y autonomía de los sectores populares subalternos, con la intención de aportar al fortalecimiento del poder popular. Se facilita un vínculo estable con la comunidad, lo que evita el problema de las intervenciones esporádicas (Tommasino y Cano, 2016).

Una última característica de este modelo es que la relación entre estudiantes y docentes es democrática, se reconocen roles diferentes, pero hay una vinculación horizontal y un reconocimiento de que todas las partes involucradas (docentes, estudiantes y personas de las comunidades) se transforman en la praxis (Tommasino y Cano, 2016). Desde la conceptualización oficial, se ubica la acción social de la Universidad de Costa Rica y de la Escuela de Psicología en este modelo. A nivel institucional se afirma que:

La Acción Social desarrolla una relación dinámica, crítica y dialógica entre la sociedad y la Universidad, respetando todos los saberes. Fomenta procesos de aprendizaje y de transformación social con todos los sectores, para contribuir al pleno desarrollo de las capacidades 
humanas y lograr una sociedad justa, inclusiva, participativa, ambientalmente sustentable y respetuosa de los derechos humanos y la diversidad (Vicerrectoría de Acción Social, 2020).

Como se mencionó previamente, se trata de modelos en disputa, así que desde las autoridades universitarias o entre las unidades académicas pueden existir posicionamientos y prácticas diversas, sin embargo, desde el discurso oficial se concibe la acción social como una práctica transformadora que se gesta a partir de un encuentro de saberes.

\section{El modelo vinculatorio empresarial}

Se fortalece a mitad de la década de los ochenta y tiene una gran vigencia actualmente. Según Ortiz-Riaga y Morales-Rubiano (2011), se caracteriza por una tendencia mercantilista que pierde el sentido social con el que fue planteada la función de extensión, y da paso a la atención de las necesidades de las empresas; la venta de servicios, la búsqueda de rentabilidad y la formación de profesionales, atendiendo las necesidades del mercado. La universidad se vincula con los sectores que pueden pagar y estos definen la agenda de atención prioritaria (Malagón, 2006; Pérez, Lakonich, Cecchi y Rotstein, 2009; Ortiz-Riaga y Morales-Rubiano, 2011).

Diferentes personas autoras han desarrollado una crítica en torno al avance del modelo empresarial en las universidades públicas, porque genera una dinámica de desarrollo muy parecida a la de las sociedades modernas: se aparta, excluye y separa a gran parte de la población del sistema de relaciones sociales, económicas y políticas (Pérez, Lakonich, Cecchi y Rotstein, 2009), con lo que se pierde el fin del bien común.

Como se puede apreciar, los modelos de extensión universitaria nos posicionan frente a discusiones teóricas, éticas, políticas, metodológicas y epistemológicas sobre el vínculo universidad-sociedad, las nociones de cambio y transformación social, la formación profesional, los modelos pedagógicos, el cambio curricular, el rol docente, entre otros temas. Es así que, como reflejo también de la diversidad de concepciones, estos modelos de extensión conviven y se combinan, haciendo de la extensión universitaria un campo heterogéneo y en disputa permanente.

Este recorrido por los diferentes modelos no tiene un fin solo descriptivo y sintetizador, también establece un marco de referencia para el balance sobre los aprendizajes y la ruta a seguir, aspectos que se retomarán posteriormente en el análisis de los resultados de la sistematización de la experiencia de acción social de la Escuela de Psicología, en el período 2000-2015. 


\section{Aspectos metodológicos}

La investigación se realizó teniendo como referencia la sistematización crítica de experiencias como una propuesta metodológica. Según Jara (2009), esta ha sido construida en América Latina a partir de los aportes de la educación popular y la investigación-acción participativa. En el proceso se sistematiza no solo la información y los datos, sino la experiencia, entendida como el conjunto de procesos vitales que forman parte de los proyectos.

A grandes rasgos, la sistematización crítica de experiencias se sitúa epistemológicamente en la investigación cualitativa y, más particularmente, en la epistemología del encantamiento, la cual ubica los objetos de investigación en el marco de las relaciones sociales, de tal manera que la subjetividad de quien investiga está implicada en la producción de conocimiento: este no es neutro, sino un resultado directo de las relaciones sociales en que se construye (Dobles, 2018).

La sistematización de experiencias es una interpretación crítica que se hace a partir del ordenamiento y de la reconstrucción de una experiencia, lo que descubre o explicita la lógica del proceso vivido, incluyendo los diversos factores que intervinieron y la relación que tuvieron entre sí. Como resultado, se producen aprendizajes significativos que posibilitan apropiarse de la experiencia, comprenderla teóricamente y orientar acciones hacia el futuro (Jara, 2011).

Una experiencia se articula a partir de condiciones del contexto, situaciones particulares, acciones, aspectos emocionales, relaciones interpersonales, resultados obtenidos, entre otros aspectos. Por ende, se asume que está en permanente movimiento y produce cambios y transformaciones (Jara, 2009).

Otra característica inherente a la sistematización de experiencias es que es participativa, es decir, se trata de un proceso "donde cada participante aporta desde su experiencia individual para construir una visión colectiva de la experiencia realizada" (Bickel, 2006, p. 2). Aunque parezca evidente, debe explicitarse que desde esta metodología el fin último es sistematizar una práctica particular en el contexto y las condiciones en que se dio. Si bien esto puede derivar en una propuesta teórica y propiciar un diálogo crítico, no tiene pretensiones de generalización ni de universalización.

Es una reconstrucción de la experiencia, ya que el análisis parte del presente. Sin embargo, esta no se centra en los resultados o en el impacto, sino en el proceso que se desarrolló, incluyendo al menos los hitos, las coyunturas, los avances, las tensiones, las rupturas, los retrocesos y los aprendizajes (Bickel, 
2006). Por lo tanto, permite revisar, rectificar y reimpulsar. Dicho en otras palabras, una sistematización crítica de la experiencia de acción social permite identificar aspectos institucionales, académicos y administrativos que han fortalecido o limitado el alcance de los proyectos, con lo cual se brindan insumos muy importantes para la toma de decisiones orientadas a potenciar el vínculo entre la universidad y la sociedad.

La sistematización de experiencias puede tener diferentes objetivos. Esta investigación particular buscó comprender a profundidad la experiencia de acción social de la Escuela de Psicología; en otras palabras, descubrir aciertos, errores, formas de superar obstáculos y dificultades o retos (Jara, 2011).

Para lo anterior se cubrieron tres ejes en el abordaje metodológico: ordenar y reconstruir el proceso vivido, realizar una interpretación crítica del mismo y extraer aprendizajes y compartirlos (Jara, 2011). Se establecieron cinco fases:

Fase 1. La delimitación de la experiencia. La definición de la sistematización de la experiencia de la acción social de la Escuela de Psicología en el período 2000-2015 fue definida por la Comisión de Investigación, por medio de la convocatoria a los proyectos para el año 2019. Adicionalmente, se cumplieron los criterios de Jara (2011), quien señala dos requisitos. El primero de ellos es haber participado en la experiencia, lo que la investigadora cumple parcialmente, ya que ha estado involucrada en la acción social de la Escuela de Psicología desde el año 2012. El segundo requisito es la existencia de registros, los cuales están disponibles en el archivo de la unidad académica.

Fase 2. Las preguntas iniciales para la planificación de la sistematización. La planificación permitió una clara delimitación de la experiencia a partir de cinco preguntas orientadoras:

¿Para qué queremos hacer esta sistematización? Primero, para buscar coherencia para el trabajo de la unidad académica, ubicándola como una oportunidad de reflexión crítica y aprendizaje. Segundo, para plantear una síntesis del camino recorrido, que permita avanzar a nuevas etapas, para así consolidar las buenas prácticas y permitir la búsqueda de estrategias de mejora en los aspectos identificados.

¿Cuál experiencia queremos sistematizar? Se sistematizó la experiencia de la Escuela de Psicología en el área de acción social (2000-2015), incluyendo aspectos administrativos, éticos, políticos y académicos que han guiado el trabajo en esta área. 
Revista Universidad en Diálogo • Vol. 11, N. ${ }^{\circ}$ 1, Enero-Junio, 2021 • 103-133

ISSN 2215-2849 • EISSN: 2215-4752

URL: http://www.revistas.una.ac.cr/index.php/dialogo/index CorReo ElECTRÓNICO: universidadendialogo@una.cr DOI: http://doi.org/10.15359/udre.11-1.4

¿Qué aspectos centrales de esas experiencias nos interesa sistematizar? Se definieron como ejes de interés el posicionamiento de acción social de la Escuela de Psicología, las estrategias de vinculación entre acción social, docencia e investigación, las estrategias de divulgación (publicaciones, prensa) y devolución a las comunidades, la capacitación a docentes: temáticas identificadas y esfuerzos realizados, la evaluación de los proyectos de acción social, el alcance de los proyectos respecto a ejes temáticos, poblaciones y distribución geográfica, las buenas prácticas de acción social, las imitaciones, tensiones, conflictos o contradicciones y formas de resolución y, finalmente, los retos.

¿Qué fuentes de información vamos a utilizar? Se definieron como fuentes de información los archivos de la Escuela de Psicología y personas que desde diferentes puestos han tenido vinculación con la acción social durante el período de estudio.

¿Qué procedimientos vamos a seguir? Se utilizaron tres técnicas de investigación: revisión documental y entrevistas no estructuradas (para construir la línea del tiempo) y un taller (para presentar y validar la línea del tiempo).

Fase 3. Recuperación del proceso vivido. Esta fase dio cuenta del proceso vivido. La revisión documental fue una etapa para conocer y organizar la información del período de estudio que respondía a los objetivos. En el archivo de la Escuela de Psicología se revisaron al menos noventa cajas etiquetadas bajo categorías vinculadas a la acción social. Se ubicaron Actas de la Comisión de Acción Social (CAS), informes anuales de la CAS, archivos de cada proyecto con correspondencia, formulaciones, informes y publicaciones, ponencias presentadas en congresos u otras actividades, entre otros documentos.

Como resultado, se construyó una línea del tiempo donde se detalló fecha (mes y año), hecho, actores clave, objetivos buscados, resultados y referencias. El resultado fue una primera versión de la línea del tiempo (documento de sesenta y cinco páginas) con información precisa sobre fechas, hechos y actores. Además, facilitó la construcción de otros documentos, tales como una base de datos de los proyectos vigentes en el período, un registro de proyectos por fecha y de los documentos disponibles (por ejemplo, actas, formulaciones e informes de proyectos). En este momento el objetivo fue ordenar y clasificar la información, no emitir conclusiones o interpretaciones, aunque sí se anotaron ejes de interés para profundizar posteriormente. Sin embargo, al hacer el balance se pudo apreciar que los registros aludían a hechos aislados con un fuerte énfasis en comunicaciones administrativas, mas no en las decisiones académicas y políticas. 
En un segundo momento se realizaron catorce entrevistas según la siguiente distribución: cuatro personas que estuvieron en la dirección de la Escuela, tres que coordinaron la CAS, tres que estuvieron en puestos administrativos vinculados a la acción social y tres que coordinaron proyectos, todas ellas dentro del período en estudio. Las entrevistas fueron exploratorias y tuvieron como objetivo recopilar información descriptiva sobre los hechos relativos a la acción social que las personas consideraron relevante. Se utilizó una guía de entrevista semiestructurada que permitió completar la línea del tiempo al facilitar la comprensión de los procesos, aspecto que se abordará en la sección de resultados.

Fase 4. La reflexión de fondo ¿por qué pasó lo que pasó? Según Bickel (2006), la interpretación debe ser un ejercicio colectivo, aunque las personas participen en diferentes espacios y momentos. A diferencia de los momentos anteriores que tienen un fin descriptivo, en esta fase se hizo un análisis de la información a partir de una interpretación crítica de la línea del tiempo y de las interrogantes que se habían identificado. El espacio fue un taller donde participaron seis docentes de la Escuela (la mayoría como seguimiento a la entrevista) e integrantes actuales de la CAS. En este se presentó la línea del tiempo y se construyó de manera grupal un balance sobre los ejes de interés más importantes, los cuales se analizan en la sección de resultados.

Fase 5. Los puntos de llegada, las conclusiones. El balance final de la explicitación de los aprendizajes que se lograron del proceso fue un trabajo del equipo de investigación a partir del análisis de los resultados del taller y la elaboración del informe final del proyecto y este artículo.

\section{Presentación de resultados y discusión}

\section{Caracterización de la acción social de la Escuela de Psicología}

En primera instancia, se presenta una caracterización general de los proyectos de acción social de la Escuela de Psicología, aunque se debe mencionar que una de las limitaciones de la investigación es que hay registros incompletos.

En el período estudiado hubo setenta y un proyectos vigentes: cincuenta y siete en la modalidad de extensión docente, doce de trabajo comunal universitario (TCU) y dos de extensión cultural. Estas modalidades han sido definidas institucionalmente.

El trabajo comunal universitario, acordado en el III Congreso Universitario (1971-1972), es la actividad interdisciplinaria realizada por estudiantes en relación recíproca con la comunidad. Es obligatorio para la graduación a nivel de grado. Es responsabilidad de cada unidad académica coordinar proyectos 
Revista Universidad en Diálogo • Vol. 11, N. ${ }^{\circ}$ 1, Enero-Junio, 2021 • 103-133

ISSN 2215-2849 • EISSN: 2215-4752

URL: http://www.revistas.una.ac.cr/index.php/dialogo/index CORREO ELECTRÓNICO: universidadendialogo@una.cr DOI: http://doi.org/10.15359/udre.11-1.4

con el objetivo de desarrollar sensibilidad en el estudiantado, por medio de la interacción con los problemas de la realidad social (Pérez y Meoño, 2005).

La modalidad de extensión docente proyecta la capacidad académica de la universidad hacia el resto de la sociedad. Incluye la educación continua (Universidad de Costa Rica, 2001). Finalmente, la extensión cultural tiene el mismo objetivo, pero utiliza la expresión cultural como medio de vinculación (Universidad de Costa Rica, 2008).

Un primer análisis de la información muestra que un $40 \%$ de los proyectos inscritos en la unidad académica de la Escuela de Psicología durante el período 2000-2015 se financiaron mediante la modalidad de vínculo remunerado ${ }^{3}$, sin embargo, todos ellos fueron inscritos como extensión docente y representan la mitad de los proyectos de esta modalidad. Por su parte, TCU y extensión cultural en su totalidad se han desarrollado con fondos del presupuesto ordinario (ver Figura 1).

\section{Figura 1}

Tipo de presupuesto de los proyectos de Acción Social de la Escuela de Psicología según modalidd. 2000-2015

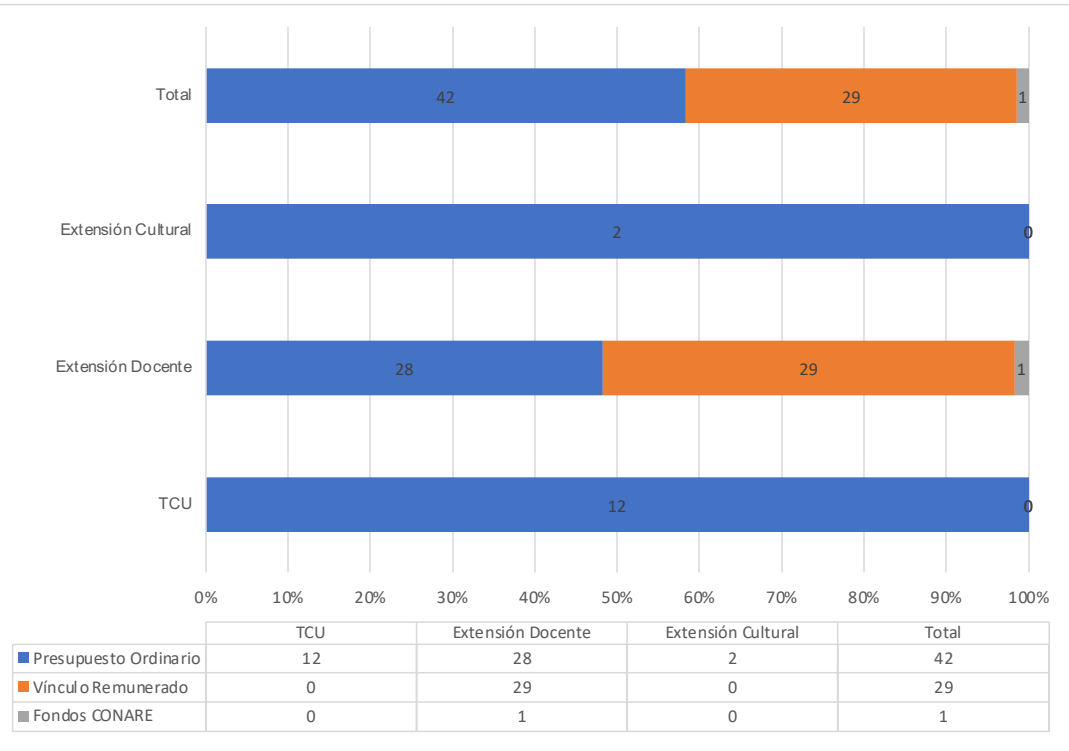

El gráfico ilustra el número de proyectos según modalidad y financiamiento.

Nota. Elaboración propia

Se denomina de esta forma a los proyectos que son financiados por medio de recursos financieros externos a la Universidad, tales como venta de servicios o financiamiento de organismos internacionales, entre otros. 
URL: http://www.revistas.una.ac.cr/index.php/dialogo/index

CORREO ELECTRÓNICO: universidadendialogo@una.cr

DOI: http://doi.org/10.15359/udre.11-1.4

Respecto a la ubicación geográfica, cerca de un $40 \%$ de los proyectos se desarrollaron en la provincia de San José, seguido de la provincia de Puntarenas y con un número significativamente menor en las provincias de Limón, Alajuela y Guanacaste. Debe tenerse en cuenta que existen proyectos con más de un lugar de incidencia y que no se cuenta con datos de ubicación para un $23 \%$ de los proyectos inscritos durante el período 2000-2015 (ver Figura 2).

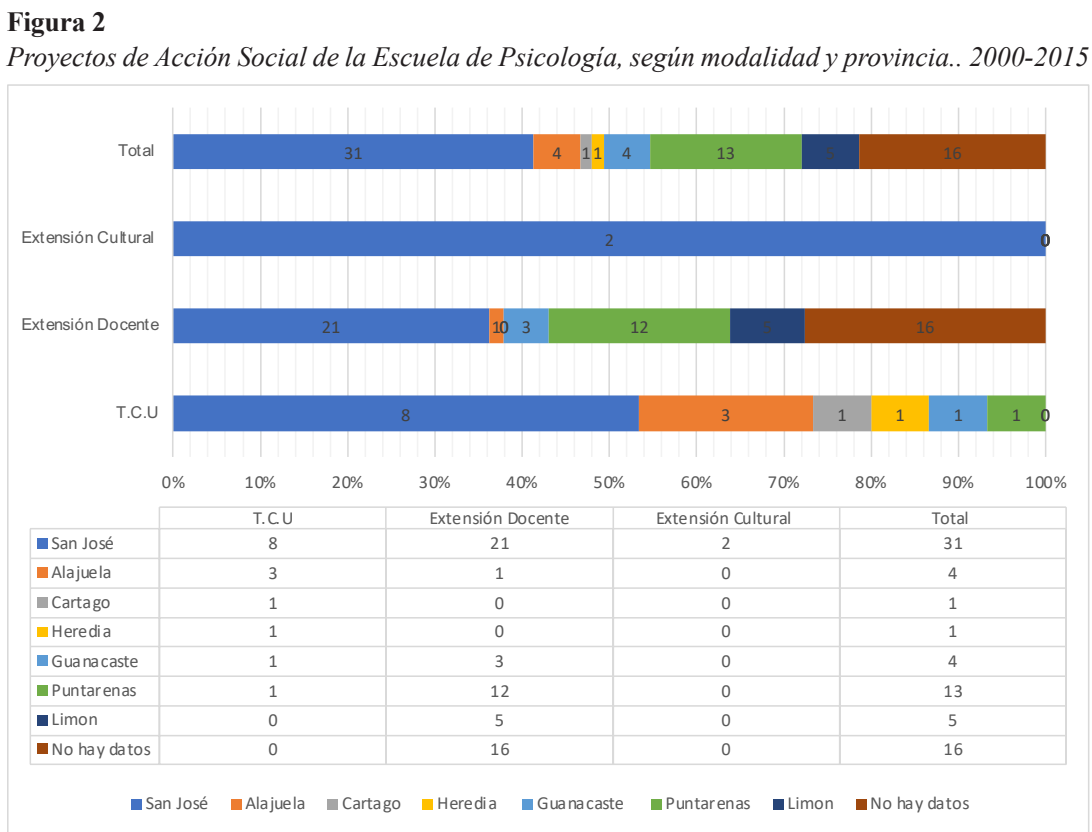

El gráfico ilustra el número de proyectos que se ha desarrollado en cada provincia según modalidad.

Nota. Elaboración propia

Las temáticas de los proyectos requieren una discusión de fondo desde la Escuela de Psicología para definir las categorías, así que los resultados que se presentan se basan en una clasificación institucional que se hace a través del programa de gestión de proyectos y tienen solo un fin descriptivo. Las categorías tienen la dificultad de que varios proyectos pueden abarcar más de una categoría, pero se definió como la principal la que esté enunciada en su título u objetivo general. La temática que más se aborda es derechos humanos, seguida de salud mental y desarrollo comunitario (ver Figura 3). 
Revista Universidad en Diálogo • Vol. 11, N. ${ }^{\circ}$ 1, Enero-Junio, 2021 • 103-133

URL: http://www.revistas.una.ac.cr/index.php/dialogo/index CorReo electrónico: universidadendialogo@una.cr DOI: http://doi.org/10.15359/udre.11-1.4

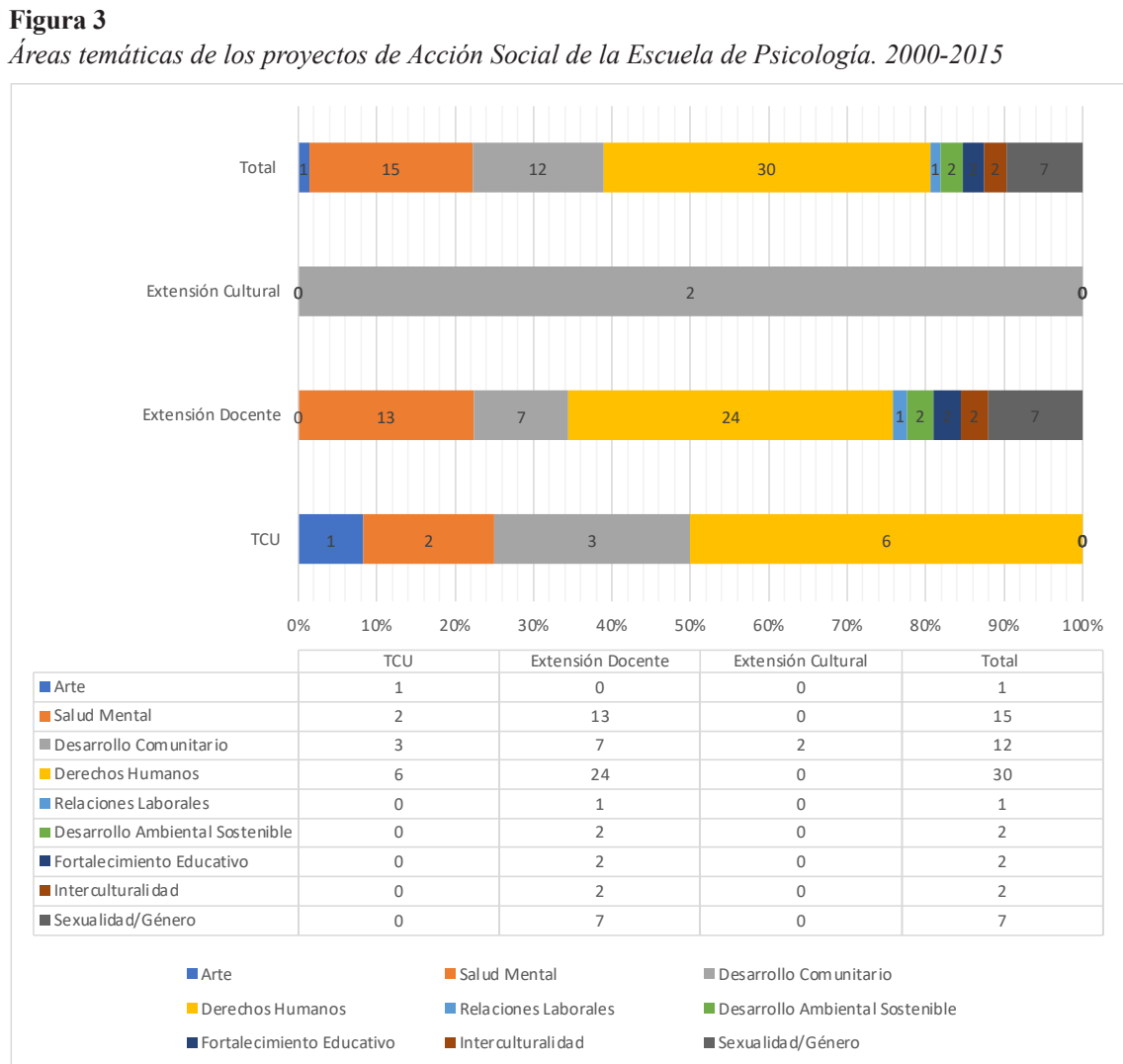

El gráfico ilustra el número de proyectos por temática según modalidad.

Nota. Elaboración propia

Respecto al personal, se documentaron ochenta y tres docentes que coordinaron proyectos en el período 2000-2015, con una distribución de cuarenta mujeres, veintiún hombres y no hay datos para veintidós casos. La presencia mayoritaria de mujeres no tiene distinción por modalidad (ver Figura 4).

Por otro lado, seis docentes tienen grado de bachillerato, diecinueve de licenciatura, veintisiete de maestría, ocho de doctorado y no hay datos para veintitrés profesionales (ver Figura 5).

Respecto a la situación laboral, treinta y nueve docentes tenían condición de interinazgo, veintiún docentes se encontraban en propiedad y para veintitrés no se encontraron datos (ver Figura 6). 
URL: http://www.revistas.una.ac.cr/index.php/dialogo/index

CORREO ELECTRÓNICO: universidadendialogo@una.cr

DOI: http://doi.org/10.15359/udre.11-1.4

\section{Figura 4}

Sexo de docentes que han coordinado proyectos de Acción Social en la Escuela de Psicología. 2000-2015

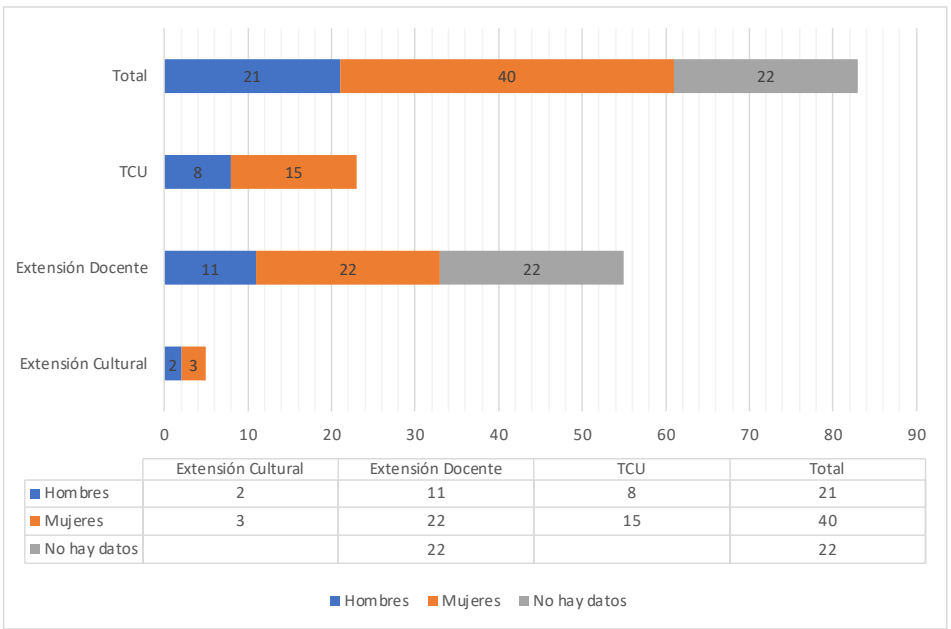

El gráfico ilustra el sexo del personal docente que ha coordinado los proyectos según modalidad.

Nota. Elaboración propia

\section{Figura 5}

Grado Académico de docentes que han coordinado proyectos de Acción Social en la Escuela de Psicología. 2000-2015

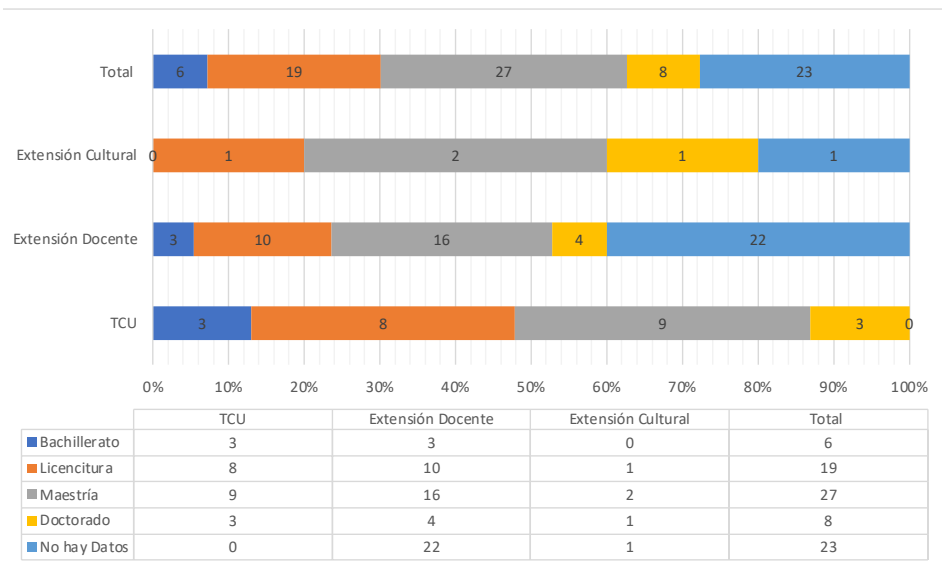

El gráfico ilustra el grado académico del personal docente que ha coordinado los proyectos según modalidad.

Nota. Elaboración propia 
Revista Universidad en Diálogo • Vol. 11, N. ${ }^{\circ}$ 1, Enero-Junio, 2021 • 103-133

URL: http://www.revistas.una.ac.cr/index.php/dialogo/index CORREO ELECTRÓNICO: universidadendialogo@una.cr DOI: http://doi.org/10.15359/udre.11-1.4

\section{Figura 6}

Condición laboral de docentes que coordinaron proyectos de Acción Social de la Escuela de Psicología. 2000-2015

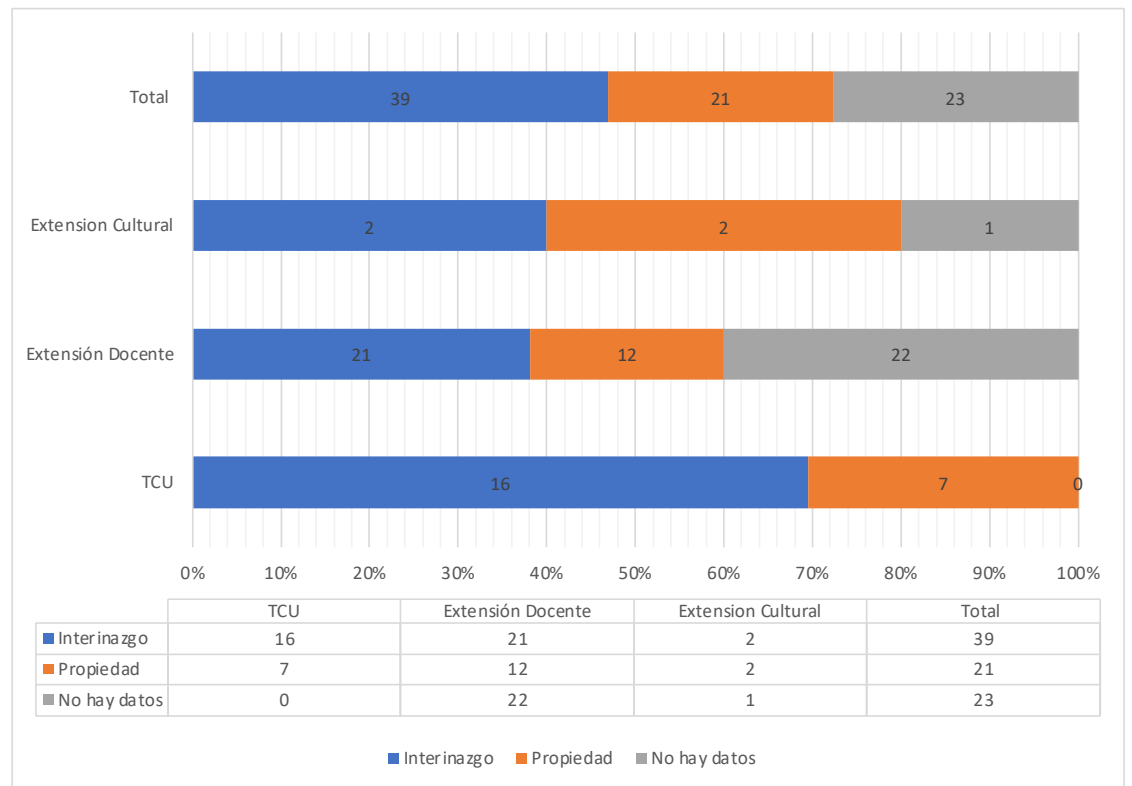

El gráfico ilustra la condición laboral del personal docente que ha coordinado los proyectos según modalidad.

Nota. Elaboración propia

Se puede suponer que estos datos faltantes son del personal interino, ya que caso contrario los registros se encuentran actualizados en los sistemas. Si esta hipótesis es correcta, un $75 \%$ del personal docente se ha vinculado con la acción social en condición de interinazgo. Por lo tanto, la conclusión es que la mayoría de docentes que ha coordinado proyectos de acción social durante el período 2000-2015 han sido mujeres en condición de interinazgo.

En otro orden del análisis, se presentan los principales ejes identificados en el proceso de sistematización crítica de la experiencia de Acción Social de la Escuela de Psicología de la Universidad de Costa Rica en el período 20002015. La Tabla 1 presenta una síntesis del balance de cada eje. 
URL: http://www.revistas.una.ac.cr/index.php/dialogo/index

CORREO ELECTRÓNICO: universidadendialogo@una.cr

DOI: http://doi.org/10.15359/udre.11-1.4

Tabla 1

Balance de avances y retos en la experiencia de Acción Social de la Escuela de Psicología de la Universidad de Costa Rica, 2000-2015

\begin{tabular}{|c|c|c|}
\hline EJE & Avances & Retos \\
\hline Posicionamiento político & $\begin{array}{l}\text { - Posicionamiento } \\
\text { construido colectivamente. } \\
\text { - Se ubica en el modelo concientizador, } \\
\text { crítico o social. } \\
\text { - Elaboración de documentos internos } \\
\text { (Políticas, Lineamientos, ponencias). }\end{array}$ & \\
\hline $\begin{array}{l}\text { La acción social como } \\
\text { parte de la } \\
\text { formación profesional }\end{array}$ & $\begin{array}{l}\text { - Desde los proyectos se enmarca } \\
\text { la acción social como un eje de la } \\
\text { formación profesional. }\end{array}$ & $\begin{array}{l}\text { - Posicionamiento desde la } \\
\text { Unidad académica. }\end{array}$ \\
\hline $\begin{array}{l}\text { Pertinencia de la } \\
\text { acción social }\end{array}$ & $\begin{array}{l}\text { - Se abordan temáticas de } \\
\text { relevancia nacional. } \\
\text { - Se han planteado "modelos de atención". }\end{array}$ & \\
\hline Vinculación de actores & $\begin{array}{l}\text { Trabajo en equipo entre Dirección, } \\
\text { Comisión de Acción Social, personal } \\
\text { administrativo y docentes que } \\
\text { coordinan proyectos. }\end{array}$ & \\
\hline $\begin{array}{l}\text { Fortalecimiento de la } \\
\text { CAS y la acción social }\end{array}$ & $\begin{array}{l}\text { - Consolidación en la integración } \\
\text { de la CAS. } \\
\text { - Seguimiento administrativo y } \\
\text { académico a proyectos. } \\
\text { - Cultura de rendición de } \\
\text { cuentas (informes). } \\
\text { - Identificación de necesidades } \\
\text { de capacitación. } \\
\text { - Carga académica para proyectos. } \\
\text { - Nombramiento en Docencia. } \\
\text { - Nombramientos interciclo y } \\
\text { con continuidad. } \\
\text { - Bodega y cubículo de Acción Social. } \\
\text { - Apoyo desde la Dirección para } \\
\text { apertura de proyectos de Trabajo } \\
\text { Comunal Universitario. }\end{array}$ & \\
\hline $\begin{array}{l}\text { CAS ampliada y la } \\
\text { reflexión permanente }\end{array}$ & $\begin{array}{l}\text { - Consolidación del espacio. } \\
\text { - Generación de políticas/lineamientos/ } \\
\text { posicionamientos. } \\
\text { - Posicionamiento de } \\
\text { demandas colectivas. } \\
\text { - Identidad colectiva. }\end{array}$ & $\begin{array}{l}\text { - Articulación sistemática } \\
\text { entre proyectos. }\end{array}$ \\
\hline
\end{tabular}


Revista Universidad en Diálogo • Vol. 11, N. ${ }^{\circ}$ 1, Enero-Junio, 2021 • 103-133

ISSN 2215-2849 • EISSN: 2215-4752

URL: http://www.revistas.una.ac.cr/index.php/dialogo/index CORREO ELECTRÓNICO: universidadendialogo@una.cr DOI: http://doi.org/10.15359/udre.11-1.4

\begin{tabular}{|c|c|c|}
\hline EJE & Avances & Retos \\
\hline Gestión administrativa & $\begin{array}{l}\text { - Identificación de necesidades y } \\
\text { seguimiento para su cumplimiento. } \\
\text { - Puestos administrativos vinculados a } \\
\text { los proyectos. } \\
\text { - Sistema de vales. } \\
\text { - Fondo de Trabajo. } \\
\text { - Organización de fechas internas } \\
\text { para trámites. }\end{array}$ & $\begin{array}{l}\text { - Mejorar la comunicación en } \\
\text { algunos procesos administrativos. } \\
\text { - Archivo }\end{array}$ \\
\hline $\begin{array}{l}\text { Experiencias de } \\
\text { vinculación entre acción } \\
\text { social, docencia e } \\
\text { investigación }\end{array}$ & $\begin{array}{l}\text { Experiencias de vinculación: } \\
\text { - Proyectos-cursos/módulos. } \\
\text { - Trabajos finales de } \\
\text { investigación e investigaciones. } \\
\text { - Publicaciones. }\end{array}$ & $\begin{array}{l}\text { - Estrategia para establecer las } \\
\text { formas de vinculación. } \\
\text { - Participación Estudiantil como } \\
\text { práctica profesionalizante }\end{array}$ \\
\hline $\begin{array}{l}\text { Consolidación/ } \\
\text { institucionalización de } \\
\text { proyectos de la } \\
\text { unidad académica }\end{array}$ & $\begin{array}{l}\text { - Proyectos que han logrado un } \\
\text { lugar "no definido" en la estructura } \\
\text { institucional y permiten articular } \\
\text { investigación y docencia (ED-74, } \\
\text { ED-2157 y ED-2586). }\end{array}$ & $\begin{array}{l}\text { - Clarificar el lugar dentro de la } \\
\text { estructura institucional. }\end{array}$ \\
\hline $\begin{array}{l}\text { Vínculo externo } \\
\text { remunerado }\end{array}$ & $\begin{array}{l}\text { - Vinculación en función de los } \\
\text { objetivos y la pertinencia y no de } \\
\text { criterios económicos. } \\
\text { - Aprobación de directrices. }\end{array}$ & \\
\hline $\begin{array}{l}\text { Vínculos con otras } \\
\text { unidades académicas }\end{array}$ & - Experiencias particulares. & $\begin{array}{l}\text { - Definición estratégica de la } \\
\text { vinculación, con otras unidades } \\
\text { académicas, incluyendo } \\
\text { sedes regionales. }\end{array}$ \\
\hline $\begin{array}{l}\text { Difusión y divulgación } \\
\text { del quehacer de } \\
\text { acción social }\end{array}$ & $\begin{array}{l}\text { Experiencias (no sostenibles): boletines, } \\
\text { información en pizarras o en la página } \\
\text { web, presentación en Asambleas } \\
\text { de Escuela, Ferias de proyectos, } \\
\text { producción audiovisual y redes sociales. }\end{array}$ & $\begin{array}{l}\text { - Estrategia (a lo interno y a lo } \\
\text { externo) bajo líneas de proyección } \\
\text { a las comunidades y } \\
\text { rendición de cuentas. } \\
\text { - Participación Estudiantil. }\end{array}$ \\
\hline $\begin{array}{l}\text { Sistematización y } \\
\text { evaluación de proyectos }\end{array}$ & $\begin{array}{l}\text { - Experiencias (no exitosas) de } \\
\text { sistematización. } \\
\text { - Experiencias de capacitación } \\
\text { en evaluación. }\end{array}$ & $\begin{array}{l}\text { Estrategia diseñada para } \\
\text { establecer la sistematización } \\
\text { y evaluación en el ciclo de los } \\
\text { proyectos. }\end{array}$ \\
\hline $\begin{array}{l}\text { Ciclo de vida de } \\
\text { los proyectos }\end{array}$ & & $\begin{array}{l}\text { Identificación de criterios para el } \\
\text { cierre de los proyectos. }\end{array}$ \\
\hline $\begin{array}{l}\text { Articulación entre } \\
\text { proyectos }\end{array}$ & - Experiencias puntuales. & $\begin{array}{l}\text { - Estrategia de vinculación } \\
\text { de proyectos. }\end{array}$ \\
\hline
\end{tabular}

Es una tabla que presenta un balance de los ejes que se analizan en los resultados.

Nota: Elaboración propia. 
URL: http://www.revistas.una.ac.cr/index.php/dialogo/index

CORREO ELECTRÓNICO: universidadendialogo@una.cr

DOI: http://doi.org/10.15359/udre.11-1.4

\section{Posicionamiento político}

Para la Escuela de Psicología ha sido muy importante construir de manera colectiva un posicionamiento ético y político sobre cómo se concibe la acción social, lo cual se ha traducido en la aprobación de diversos lineamientos que orientan ese quehacer. Esto incluye políticas internas de la unidad académica, que, en consonancia con las políticas institucionales, abordan los ejes de los Principios de la acción social, pertinencia y relevancia social, integración académica, vinculación externa remunerada y fortalecimiento docente. Además, las Directrices para la Vinculación Remunerada con el Sector Externo, que contemplan aspectos éticos, económicos y operativos.

Asimismo, los fines buscados se corresponden con los planteados en el Estatuto Orgánico, tales como contribuir a las transformaciones sociales para el logro del bien común, bajo principios de justicia social, equidad y libertad (artículo 3) y principios como la estimulación de una conciencia creativa y crítica, la búsqueda de la verdad, la justicia, la belleza, el respeto a las diferencias, la solidaridad, la formación humanista y la contribución a la construcción de un saber en relación con la realidad social (artículo 5).

Desde la CAS Ampliada de la Escuela de Psicología, la acción social se sustenta en tres ejes básicos. Primero, la vinculación academia-sociedad, la cual debe sostenerse desde una reflexión crítica que permita un posicionamiento éticopolítico frente a la realidad nacional, el fomento de un diálogo de saberes y un trabajo que en la vinculación con las poblaciones vulnerabilizadas parta de las dinámicas estructurales que propician la exclusión social, y no de una propuesta de asistencialismo social.

Segundo, la promoción de la transformación social que se gesta desde la construcción, el fortalecimiento y el empoderamiento de estructuras organizativas comunitarias, institucionales y grupales, la promoción de los derechos humanos de las poblaciones con que se trabaja y la incidencia en políticas públicas e institucionales que promuevan el bienestar y la igualdad. Y tercero, el fortalecimiento académico a través del trabajo interdisciplinario, la promoción de la acción social como un espacio integrador entre docencia e investigación y el espacio formativo para docentes y estudiantes en relación directa con comunidades, grupos e instituciones.

La extensión universitaria debe sustentarse en la capacidad crítica y el pensamiento estratégico, en función de los intereses del conjunto de la población, lo que debe decantar en un posicionamiento a favor de la población marginada y vulnerable; 
Revista Universidad En DiÁlogo • Vol. 11, N. ${ }^{\circ}$ 1, Enero-Junio, 2021 • 103-133

ISSN 2215-2849 • EISSN: 2215-4752

URL: http://www.revistas.una.ac.cr/index.php/dialogo/index CORREO ELECTRÓNICO: universidadendialogo@una.cr DOI: http://doi.org/10.15359/udre.11-1.4

debe acompañar procesos personales, grupales y comunitarios encaminados a la solución de problemas concretos, mediante una construcción conjunta con las comunidades, evitando el asistencialismo; debe entenderse como un elemento fundamental en la formación profesional que influye en la transformación de la vida social (Carlevaro, 2008; Serna, 2007; Malagón, 2006). Todos estos elementos se encuentran presentes en el posicionamiento político, por lo tanto, se puede afirmar que la acción social de la Escuela de Psicología se ubica en el modelo concientizador, de extensión crítica o enfoque social. Esta premisa no se sustenta en una evaluación de los resultados de los proyectos, sino en la definición de los principios orientadores en la documentación consultada y las entrevistas realizadas.

\section{La acción social como parte de la formación profesional}

En el posicionamiento citado anteriormente se ubica el eje de la acción social como un elemento fundamental en la formación profesional humanista; sin embargo, es un punto sobre el que interesa ampliar. Carlevaro (2008) pregunta ¿cómo se enseña y qué se aprende en ese espacio educacional nuevo que es la comunidad? La respuesta se orienta desde el diálogo de saberes como un principio epistemológico y metodológico. Este presupone horizontalidad entre docentes, estudiantes y personas de la comunidad. Es decir, los actores sociales pasan de ser objetos de estudio a ser sujetos en el planteamiento de los problemas y la construcción del conocimiento que apunta a la transformación social (Tommasino y Cano, 2016; Ortiz-Riaga y Morales-Rubiano, 2011).

Es así como la formación trasciende la disciplina para generar otras reflexiones que son igualmente significativas en el proceso formativo. Por ejemplo, el trabajo en equipos establece un marco colectivo y horizontal de gran alcance en una sociedad neoliberal en la que predomina el individualismo. Este fomenta la criticidad y la creatividad, promueve la escucha y el respeto a las otras personas (Carlevaro, 2008). El reto es que este posicionamiento sea asumido por la totalidad de la unidad académica.

\section{Pertinencia de la acción social}

Todos los proyectos de la Escuela han trabajado temáticas de relevancia en la realidad nacional (salud mental, derechos humanos de diversas poblaciones, explotación sexual comercial, gestión del riesgo, organización comunitaria, entre otras), respondiendo a las necesidades del contexto nacional y sin duplicar el trabajo de las instituciones públicas. 
Los proyectos han realizado abordajes no tradicionales que muestran grandes aprendizajes, tanto para la universidad como para la propia disciplina, para otras instituciones y para el Estado, al punto de que han alimentado la formulación de algunas políticas públicas o generado propuestas de modelos de atención. Por ejemplo, el abordaje de la salud mental desde enfoques no clínicos, la atención psicosocial de las emergencias y desastres o el trabajo con mujeres víctimas de explotación sexual comercial, solo por citar algunos ejemplos.

\section{Vinculación de actores}

Los diferentes actores de la Escuela se han vinculado de manera activa y comprometida desde el rol que les corresponde. Las personas que ocuparon el puesto de la Dirección de la Escuela y le dieron un lugar prioritario a esta actividad en el quehacer institucional impulsaron grandes avances. Con diferentes énfasis en cada gestión, estas personas tomaron decisiones y acompañaron procesos que valorados en el tiempo muestran buenas prácticas.

Las coordinaciones de la CAS tuvieron una gran claridad para identificar las limitaciones que se enfrentaban y esto permitió avanzar en el fortalecimiento de la comisión y, como resultado, en la gestión de los proyectos, tanto en su dimensión administrativa como académica. El personal docente que ha coordinado proyectos ha mostrado, en términos generales, un gran compromiso y capacidad de trabajo en equipo. Y el personal administrativo ha brindado un fuerte apoyo a la gestión de los proyectos, lo cual facilita no solo la tramitología, sino también la implementación.

\section{Fortalecimiento de la CAS y la acción social}

Se muestra un claro fortalecimiento de la Comisión en el período en estudio. En el año 2000 se contaba solo con una Coordinación de Acción Social y esta persona desempeñaba todas las tareas (excluyendo el vínculo externo remunerado que tramitaba directamente la Dirección). En el año 2005, se conformó una comisión de facto, que integraba a quienes coordinaban proyectos. En el año 2010, se nombró a dos personas y para el año 2015 la CAS estaba integrada por cinco docentes. Esto ha permitido un mejor acompañamiento académico y administrativo de los proyectos, lo cual significa que la CAS no se avoca solo a los trámites, sino que puede generar procesos de capacitación y discusión sobre el posicionamiento político, entre muchas otras labores.

Los resultados muestran que se ha mejorado en la devolución de las formulaciones de proyectos e informes, el acompañamiento ante situaciones específicas que lo ameriten, el fortalecimiento de la cultura de presentación de 
Revista Universidad en Diálogo • Vol. 11, N. ${ }^{\circ}$ 1, Enero-Junio, 2021 • 103-133

ISSN 2215-2849 • EISSN: 2215-4752

URL: http://www.revistas.una.ac.cr/index.php/dialogo/index CORREO ELECTRÓNICO: universidadendialogo@una.cr DOI: http://doi.org/10.15359/udre.11-1.4

informes y rendición de cuentas, así como la atención de ejes de trabajo, como el monitoreo y la evaluación de los proyectos.

De forma paralela, otros avances del período tienen que ver con que todos los proyectos tienen carga académica para su coordinación (excepto el ED2586 Programa de Educación Continua, que se coordinaba por recargo de la CAS); se han garantizado los nombramientos en docencia a quienes coordinan proyectos, se asignó un cubículo y una bodega específica para proyectos de acción social, a partir del 2010 se incentivó la apertura de nuevos proyectos de TCU, entre otros aspectos. Todas estas acciones en su conjunto han facilitado mejores condiciones para la gestión de los proyectos.

\section{CAS Ampliada y la reflexión permanente}

En estrecha relación con lo anterior, se ha consolidado un espacio que convoca a la CAS y a todas las coordinaciones de proyectos de acción social. Este tiene antecedentes desde inicios del período de estudio, pero se conforma bajo el nombre CAS Ampliada a partir de la convocatoria realizada en el 2010 para construir las políticas propias de la Escuela de Psicología. La Comisión se reúne de dos a tres veces al año y genera discusiones de fondo sobre el posicionamiento. Esto permitió generar las Políticas de Acción Social de la Escuela (2011) y los Lineamientos de Vínculo Remunerado (2012), además de presentar ponencias al VII Congreso Universitario (2014).

También posicionó demandas de manera colectiva ante la Escuela, a fin de generar mejores condiciones de trabajo; es un espacio de encuentro entre proyectos que ha construido una identidad colectiva desde la unidad académica. Como todo proceso grupal, tiene sus limitaciones y retos. Entre estos uno de los centrales es la coordinación sistemática entre proyectos.

\section{Gestión administrativa}

Desde la Escuela (Dirección-Jefatura Administrativa-CAS Ampliada) se han identificado necesidades administrativas para mejorar la gestión de la acción social y se han tramitado ante la Universidad. Esto no ha sido fácil, ha requerido años de esfuerzos y de seguimiento a las solicitudes, sin embargo, se han visto resultados positivos.

Entre los principales logros se pueden citar la asignación de una plaza para la encargada administrativa de los proyectos de acción social, el nombramiento de docentes en condición de interinazgo en el período interciclo, un sistema 
URL: http://www.revistas.una.ac.cr/index.php/dialogo/index

CORREO ELECTRÓNICO: universidadendialogo@una.cr

DOI: http://doi.org/10.15359/udre.11-1.4

de vales para las compras de los proyectos, un fondo de trabajo específico para acción social, puestos administrativos en dos de los proyectos que se han institucionalizado 4 y la organización de fechas internas para trámites (informes, renovaciones de proyectos, ejecución presupuestaria, etc.).

La consolidación de los puestos administrativos permitió la mejora en los procesos y, por ende, en la gestión de los proyectos, incluyendo lo logístico, lo financiero y lo académico. Es importante mencionar que en gran medida estos cambios administrativos se hicieron necesarios ante el crecimiento de proyectos de presupuesto ordinario que surgieron a partir del 2010, cuando la Dirección de la Escuela apoyó la apertura de nuevas iniciativas, lo cual demandó de manera paralela el fortalecimiento de la estructura administrativa de la Escuela.

No obstante, persisten los retos, tales como mejorar la comunicación interna sobre los resultados de los procesos administrativos de los proyectos con todas las partes involucradas y la organización del archivo.

\section{Experiencias de vinculación entre acción social, docencia e investigación}

La acción social, concebida como proceso pedagógico, altera el binomio docente-estudiante, incidiendo así en los procesos de formación profesional tanto de estudiantes como de docentes, y articulando más fluidamente la docencia con la investigación. Por lo tanto, transforma la propia universidad en la medida que genera cambios en los procesos formativos. Incorpora, en la construcción del conocimiento, a la comunidad como un nuevo actor y a las preguntas novedosas que surgen de la experiencia, generando así un enfoque investigativo, participativo y transformador.

Asimismo, la extensión también tiene un papel importante en la construcción de las agendas de investigación, ya que presenta a la academia aquellas problemáticas, temáticas y objetos de estudio que son de interés para las comunidades (Fresán, 2004; Carlevaro, 2008; Ortiz-Riaga y Morales-Rubiano, 2011; Tommasino y Cano, 2016).

En el caso analizado esta articulación se posiciona como un principio, sin embargo, se identificaron diferentes experiencias de vinculación particulares,

\footnotetext{
Se refiere a ED-74 Acompañamiento psicosocial en situaciones de emergencias y desastres, como su nombre lo indica, desde el proyecto y de manera coordinada con la Comisión Nacional de Emergencias, se trabaja en las comunidades que han sido afectadas por un desastre desde un enfoque psicosocial. Y el ED-2157 Centro de Atención Psicológica, servicio de atención clínica psicológica, dirigido a personas residentes en Costa Rica, cuyos recursos económicos les impiden acceder a este tipo de servicios de manera privada.
} 
Revista Universidad en Diálogo • Vol. 11, N. ${ }^{\circ}$ 1, Enero-Junio, 2021 • 103-133

ISSN 2215-2849 • EISSN: 2215-4752

URL: http://www.revistas.una.ac.cr/index.php/dialogo/index CoRREO ELECTRÓNICO: universidadendialogo@una.cr DOI: http://doi.org/10.15359/udre.11-1.4

pero no una estrategia diseñada. Algunos proyectos han tenido una articulación directa con los cursos del plan de estudios, lo cual significa que estudiantes de la carrera trabajan con la población de los proyectos, pero además que la experiencia de campo realimenta la práctica docente.

Por otro lado, hay proyectos que han generado publicaciones de la experiencia (libros, manuales, sistematización de buenas prácticas), o que han establecido una vinculación formal con proyectos de investigación y trabajos finales de graduación. Además, se identificaron buenas prácticas en las que la experiencia de un proyecto de gran trayectoria permitió pensar las características de los módulos 5 .

Respecto a este punto existen grandes retos. Lo más importante es diseñar una estrategia de vinculación entre los cursos y módulos con los proyectos, que otorguen a estudiantes la posibilidad de participar de manera activa en los procesos comunitarios como parte de su formación profesional y la vinculación con los proyectos de investigación, incluyendo los del Instituto de Investigaciones Psicológicas.

\section{Consolidación/institucionalización de proyectos de la unidad académica}

Entre la amplitud y variedad de proyectos, hay tres (cada uno con características específicas) que han desarrollado condiciones particulares de trabajo y han logrado un lugar "no definido" en la estructura institucional.

Estos proyectos son ED-74 Atención psicosocial ante situaciones de desastres y emergencias, ED-2157 Centro de atención psicológica y proyección comunitaria de la Escuela de Psicología y ED-2586 Programa de educación continua de la Escuela de Psicología. Los dos primeros han sido denominados Unidades de Apoyo por parte de la Rectoría, y si bien sigue sin haber respaldo en la reglamentación universitaria, cuentan con infraestructura, personal administrativo propio y un presupuesto más amplio.

En contraste, el último de los proyectos se ha coordinado ad honorem y no ha tenido presupuesto asignado; sin embargo, se garantiza su viabilidad porque se ha asumido como responsabilidad de la universidad pública ofertar

Se refiere al proyecto TC-147 Desarrollo comunitario en la zona sur, prevención de la violencia (con énfasis en explotación sexual comercial), que estuvo vigente por alrededor de 20 años y alrededor del cual se articularon otros proyectos de vínculo externo remunerado. El sistema modular de la Escuela de Psicología es una propuesta estrategia pedagógica central en el Plan de Estudios de la Escuela que integra la teoría con la inserción profesionalizante, involucrando aspectos epistemológicos, pedagógicos, éticos y políticos. Asimismo, busca integrar la docencia, la investigación y la acción social durante el semestre. 
URL: http://www.revistas.una.ac.cr/index.php/dialogo/index

CORREO ELECTRÓNICO: universidadendialogo@una.cr

DOI: http://doi.org/10.15359/udre.11-1.4

actividades que abordan temas de actualidad y pertinencia nacional, y que en su mayoría son gratuitas y abiertas a la comunidad nacional.

Señalar que estos proyectos se han consolidado de ninguna manera implica negar que a su vez presentan grandes retos y desafíos. Sin embargo, no compete a esta investigación entrar en ese análisis particular. El reto al respecto es consolidar esas particularidades en la reglamentación institucional.

\section{Vínculo externo remunerado}

El lugar del vínculo externo remunerado en la Escuela ha cambiado según la Dirección. Se pueden identificar tres momentos. Del 2000 al 2004 esta actividad no se concebía como acción social, del 2004 al 2010 se atendió como la principal actividad de acción social y a partir del 2010 se sometió a revisión la política de la Escuela y se generaron lineamientos.

Sin embargo, a pesar de estas diferencias, siempre ha existido una vinculación con otras instituciones u organizaciones que se ha establecido en función de los objetivos y la pertinencia, y no de criterios económicos. Un logro importante en esta área es la aprobación de las directrices de vínculo remunerado, porque enmarcan los aspectos económicos en las políticas de la unidad académica e incluyen criterios éticos que deben regir los proyectos.

Asimismo, se identifican algunas lecciones aprendidas. Este tipo de proyectos requieren firma de convenios y la contratación de personas que den un seguimiento cercano a su cumplimiento, ya que en caso contrario es difícil su sostenibilidad en el tiempo. Además, se debe realizar una contratación de personal, que en algunos casos incluye personas externas a la unidad académica, y esto exige velar por que se cumpla con la calidad académica que se ofrece.

Finalmente, plantea algunas interrogantes: ¿Se debe ofrecer servicios a otras instituciones del Estado?, ¿es un mecanismo éticamente válido para atender necesidades de la unidad académica que no se pueden cubrir con fondos ordinarios, tales como infraestructura o equipo?, ¿es papel de la Escuela generar opciones laborales para profesionales del área?

\section{Vínculos con otras unidades académicas}

La vinculación con otras unidades académicas es un aspecto que se planteó en las entrevistas como una experiencia positiva, sin embargo, entre proyectos son experiencias puntuales y coyunturales, más que articulaciones planificadas 
y sostenibles en el tiempo. La CAS ha buscado la articulación constante con otras comisiones, proyectos o programas, a fin de discutir sobre el modelo de acción social de la Universidad o los aprendizajes del trabajo comunitario, la resistencia frente al debilitamiento de la acción social, entre otros temas. El reto es generar esta articulación como parte de una estrategia y particularmente el encuentro con las sedes regionales.

\section{Difusión y divulgación del quehacer de la acción social}

La difusión y divulgación ha sido una tarea pendiente. Se identificaron diferentes estrategias, tales como boletines, información en pizarras o en la página web, presentación en Asambleas de Escuela, ferias de proyectos y más recientemente producción audiovisual y redes sociales. Sin embargo, la mayoría de ellas no han sido sostenibles en el tiempo.

Como reto se identifica el fortalecimiento de la divulgación a lo interno de la Escuela de Psicología y la Universidad de Costa Rica, pero también hacia lo externo, como una proyección a las comunidades y una rendición de cuentas del trabajo que se realiza, así como la participación del estudiantado en estos procesos.

\section{Sistematización y evaluación de proyectos}

Al igual que el punto anterior, la sistematización y evaluación de los proyectos son tareas que se han identificado como un reto. Lezcano (2014) advierte que la extensión universitaria usualmente tiene dos grandes fases, la planificación y la ejecución, a lo cual se puede aunar algún tipo de rendición de cuentas respecto a los recursos y los resultados.

Sin embargo, la sistematización de las experiencias suele estar ausente, lo cual es un grave error, ya que esta permite realimentar la práctica y generar nueva información que incide no solo en la acción social propiamente, sino también en la investigación y la docencia. Desde la Escuela se han impulsado experiencias particulares de sistematización de los proyectos, sin embargo, por diferentes razones, estas no han tenido los resultados esperados. En el caso de la evaluación, existen esfuerzos recientes (fuera del período de estudio) en capacitación al personal docente.

\section{Ciclo de vida de los proyectos}

En la unidad académica no existen criterios para establecer el ciclo de vida de los proyectos. Aquellos que cerraron durante el período de estudio, en 
URL: http://www.revistas.una.ac.cr/index.php/dialogo/index

CORREO ELECTRÓNICO: universidadendialogo@una.cr

DOI: http://doi.org/10.15359/udre.11-1.4

su mayoría lo hicieron debido a factores como la salida de la persona que coordinaba por diferentes motivos (pensión o desvinculación laboral).

A partir de este balance, los aprendizajes y los retos identificados en la sistematización de la experiencia de acción social de la Escuela de Psicología surgen con gran claridad, lo cual se espera que sea un aporte relevante para la toma de decisiones desde la unidad académica.

\section{Conclusiones}

Desde una perspectiva histórica, la Reforma de Córdoba es el punto de arranque, en América Latina, de un modelo de universidad que la ubica como un actor social muy importante para responder a las necesidades de las grandes mayorías y apuntar a los procesos de transformación social. Sin embargo, ha sido un modelo en disputa y más recientemente se ha fortalecido una universidad orientada al mercado.

En la concepción de la universidad-empresa la acción social es una función aislada y marginal, cuando no un medio de obtención de recursos a través del vínculo externo remunerado, pero existe una gran paradoja. A lo interno de las universidades, esta actividad relegada tiene menor presupuesto y valor académico, y no ocupa un lugar destacado en la agenda política y programática de la internacionalización de la educación superior; pero es la principal herramienta de defensa de las universidades en momentos de crisis, de ataques y de recorte presupuestario (Tommasino y Cano, 2016). Por lo tanto, es un momento en que la reflexión académica en torno a la extensión universitaria es de gran importancia, pero más aún la articulación de acciones para su defensa.

En el caso particular de la Universidad de Costa Rica, la acción social, la docencia y la investigación son las tres actividades sustantivas reconocidas en el Estatuto Orgánico y la normativa universitaria en general. La acción social establece una relación dialógica entre la academia y la sociedad, que, desde su enunciación, tanto a nivel de la institución como de la unidad académica en particular, se ubica en el modelo concientizador, crítico o social.

En el análisis se identificaron tres momentos en la gestión de la acción social de la Escuela de Psicología, los cuales están ligados en gran medida a los cambios en la Dirección de la Escuela. Al respecto se deben hacer dos acotaciones. Por un lado, el apoyo de la directora o del director de la unidad académica es fundamental para el quehacer de los proyectos; sin embargo, no se puede obviar que se trata de procesos que van mostrando sus resultados en 
períodos particulares, pero que deben entenderse - en algunos casos - desde las acciones emprendidas en momentos previos.

1. Período 2000-2004. La acción social no se asume como un eje central del quehacer de la unidad académica. Existe una Coordinación de Acción Social, tres proyectos de TCU y dos de extensión docente de manera permanente. Las iniciativas de vínculo externo remunerado no se consideran acción social y estas se tramitan por otras vías administrativas.

2. Período 2004-2009. Existe una Coordinación de Acción Social, se mantienen vigentes los proyectos mencionados y se da un fortalecimiento de los proyectos de vínculo externo remunerado. Esto no obedece a una política planteada de manera explícita, sino a un apoyo de la Dirección de la Escuela a las iniciativas presentadas por docentes.

3. Período 2010-2015. Se constata un claro fortalecimiento de la acción social. Paulatinamente se integra una Comisión de Acción Social (pasa de una persona a cinco), se aprueban las Políticas de Acción Social de la Escuela y las Directrices para el Vínculo Externo Remunerado, se consolidan los proyectos del CAP y la Brigada con plazas administrativas e instalaciones, las actividades de extensión docente se organizan bajo el Programa de Educación Continua, se logran los nombramientos en continuidad de quienes coordinan TCU, se cuenta con un cubículo asignado a los proyectos, se generan cambios en la gestión administrativa de los proyectos que favorecen su ejecución y se da la apertura de nuevos proyectos de TCU, entre muchos otros aspectos.

Entre los principales factores que contribuyeron a ese fortalecimiento de la acción social en el período 2010-2015 se pueden citar los siguientes:

1. Un compromiso desde la Dirección de la Escuela por fortalecer la acción social como una actividad sustantiva del quehacer de la unidad académica

2. Una claridad política de la acción social que se impulsa desde la Escuela, especialmente a partir de la conformación y del fortalecimiento de la CAS Ampliada.

3. Un trabajo en equipo entre el personal administrativo y el personal docente responsable de los proyectos, elemento que sí es común a todo el período. 
Algunos autores (Carlevaro, 2008; Serna, 2007) identifican errores que se han cometido históricamente en la vinculación entre la universidad y la sociedad. Uno de ellos es la falta de claridad sobre la naturaleza y los fines de esa relación, así como la discusión ética sobre las implicaciones del vínculo. Sin la presencia constante de la reflexión, existe el riesgo de extraer conocimiento sin generar ningún aporte a las personas o realizar labores meramente asistenciales. "En lugar de poner la universidad al servicio del pueblo, se pone la comunidad a disposición de nuestras necesidades" (Carlevaro, 2008, p. 22).

En este sentido, la experiencia analizada muestra una buena práctica al mantener el posicionamiento ético-político como una constante en el trabajo y esto orienta los resultados que se obtuvieron durante el período de análisis.

Sin bien se identifican retos en diferentes ejes de análisis, cinco de ellos son los prioritarios: la divulgación, la sistematización y evaluación de los proyectos, los criterios para el ciclo de vida de los proyectos, el diseño de estrategias para una vinculación sostenida de los proyectos con la docencia y la investigación, y la articulación de los proyectos vigentes por criterios como temáticas, población o área territorial. Estos dos últimos ejes orientados tanto a lo interno como a otras unidades académicas. El trabajo articulado mediante programas ha sido identificado como una buena práctica (Tommasino y Cano, 2016).

\section{Referencias}

Acevedo, A. (2010). A cien años de la Reforma de Córdoba, 1918-2018. La época, los acontecimientos, el legado. Historia y Espacio, 36, 1-14. ISSN-e 0120-4661, 7. 10.25100/hye.v7i36.1784

Bickel, A. (2006). La sistematización participativa para descubrir los sentidos y aprender de nuestras experiencias. http://www.cepalforja.org/sistem/ bvirtual $/ \mathrm{p}=660$

Carlevaro, P. (2008). Universidad y sociedad: proyección y vínculos. Reencuentro, 52, 19-37.

Dobles, I. (2018). Investigación cualitativa, metodología, relaciones y ética. San José: Editorial UCR.

Fresán, M. (2004). La extensión universitaria y la Universidad Pública. Reencuentro, 39, 47-54. 
Jara-Holliday, O. (2009). La sistematización de experiencias y las corrientes innovadoras del pensamiento latinoamericano-una aproximación histórica. Diálogo de Saberes, 3, 118-129.

Jara-Holliday, O.(2011). Orientaciones teórico-prácticas para lasistematización de experiencias. http://centroderecursos.alboan.org/sistematizacion/es/ registros/6793-orientaciones-teorico-practicas-para-la

Lezcano-Calderón, S. (2014). La sistematización de experiencias en la extensión universitaria y en el fortalecimiento de la relación universidad y sociedad. Universidad en Diálogo, IV(1), 81-91.

Malagón, L. (2006). La vinculación Universidad-Sociedad desde una perspectiva social. Educación y Educadores, 9(2), 79-93. ISSN 01231294. https://educacionyeducadores.unisabana.edu.co/index.php/eye/ article/view/664/749

Muñoz Solano, D. (29 de enero de 2020). UCR inicia con el presupuesto ordinario más bajo desde 2015. Semanario Universidad. $\quad$ https://semanariouniversidad.com/universitarias/ ucr-inicia-con-el-presupuesto-ordinario-mas-bajo-desde-2015/

Ortiz-Riaga, M. y Morales-Rubiano, M. (2011). La extensión universitaria en América Latina: concepciones y tendencias. Educ.Educ., 14(2), 349366. ISSN 0123-1294. https://educacionyeducadores.unisabana.edu. co/index.php/eye/article/view/1928

Pérez, D. A., Lakonich, J. J., Cecchi, N. H. y Rotstein, A. (2009). El compromiso social de la universidad latinoamericana del siglo XXI: entre el debate y la acción. Ciudad Autónoma de Buenos Aires: IEC-CONADU. http://bibliotecavirtual.clacso.org.ar/Argentina/iecconadu/20100317010331/2.pdf

Pérez-Yglesias, M. y Meoño-Molina, R. (2005). Trabajo Comunal Universitario. La conquista de un derecho. Universidad de Costa Rica, San José.

Rubens, J. (2007). La Reforma Universitaria en Brasil: aportes para el debate sobre las reformas y el modelo de la Universidad Latinoamericana. En D. Soto y M. I. Lafuente (coords.), Autonomía y modelos universitarios en América Latina (pp. 278-294). Universidad de León, España. Rudecolombia. 
Rincón, C. (2007). La Autonomía y Die Autono: la herencia del movimiento de la reforma de Córdoba y el modelo Humboldt. En D. Soto y M. I. Lafuente (coords.), Autonomía y modelos universitarios en América Latina (pp. 125-134). Universidad de León, España. Rudecolombia.

Serna, G. (2007). Misión social y modelos de extensión universitaria: del entusiasmo al desdén. Revista Iberoamericana de Educación, 43(3), 1-7. ISSN 1681-5653.

Tommasino, H. y Cano, A. (2016). Modelos de extensión universitaria en las universidades latinoamericanas en el siglo XXI: tendencias y controversias. Universidades, 67, 7-24. ISSN 0041-8935.

Tünnermann, C. (2008). La Reforma de Córdoba. Vientre fecundo de la transformación universitaria. La reforma universitaria: desafios $y$ perspectivas noventa años después. Buenos Aires: Consejo Latinoamericano de Ciencias Sociales Editorial/Editor.

Universidad de Costa Rica. (1973). Asamblea Universitaria: acuerdos definitivos originados en el III Congreso Universitario 1971-1972 (136782). [Publicación Institucional]. Ciudad Universitaria Rodrigo Facio, San José, Costa Rica.

Universidad de Costa Rica. (1985). Vicerrectoría de Acción Social. Trabajo Comunal Universitario: vínculo entre la universidad y la comunidad (683455). [Publicación Institucional]. Oficina de Publicaciones de la Universidad de Costa Rica. Ciudad Universitaria Rodrigo Facio, San José, Costa Rica.

Universidad de Costa Rica. (2001). Vicerrectoría de Acción Social (534056). [Publicación Institucional]. Ciudad Universitaria Rodrigo Facio, San José, Costa Rica.

Universidad de Costa Rica. (2008). Una Universidad que piensa y actúa en tres dimensiones: Docencia, Investigación y Acción Social (682856). [Publicación Institucional]. Oficina de divulgación e Información y Oficina de Asuntos Internacionales y Cooperación Externa. Ciudad Universitaria Rodrigo Facio, San José, Costa Rica.

Vicerrectoría de Acción Social. (2020). ¿Qué es acción social? https:// accionsocial.ucr.ac.cr/quienes-somos 